\title{
Antibody-Dependent Enhancement of Ebola Virus Infection
}

\author{
Ayato Takada, ${ }^{1,2 *}$ Heinz Feldmann, ${ }^{3}$ Thomas G. Ksiazek, ${ }^{4}$ and Yoshihiro Kawaoka ${ }^{1,2,5 *}$ \\ Division of Virology, Department of Microbiology and Immunology, Institute of Medical Science, University of Tokyo, \\ Tokyo 108-8639, ${ }^{1}$ and CREST, Japan Science and Technology Corporation, Saitama 332-0012, Japan ${ }^{2}$; Special Pathogens \\ Program, National Microbiology Laboratory, Canadian Science Centre for Human and Animal Health, Winnipeg, Manitoba \\ R3E 3R2, Canada ${ }^{3}$; Special Pathogens Branch, Division of Viral and Rickettsial Diseases, National Center \\ for Infectious Diseases, Centers for Disease Control and Prevention, Atlanta, Georgia 303334; \\ and Department of Pathobiological Sciences, University of Wisconsin, \\ Madison, Wisconsin $53706^{5}$
}

Received 20 December 2002/Accepted 8 April 2003

\begin{abstract}
Most strains of Ebola virus cause a rapidly fatal hemorrhagic disease in humans, yet there are still no biologic explanations that adequately account for the extreme virulence of these emerging pathogens. Here we show that Ebola Zaire virus infection in humans induces antibodies that enhance viral infectivity. Plasma or serum from convalescing patients enhanced the infection of primate kidney cells by the Zaire virus, and this enhancement was mediated by antibodies to the viral glycoprotein and by complement component C1q. Our results suggest a novel mechanism of antibody-dependent enhancement of Ebola virus infection, one that would account for the dire outcome of Ebola outbreaks in human populations.
\end{abstract}

Ebola virus infection of primates is generally characterized by severe hemorrhagic manifestations and produces higher mortality rates than any of the other viral hemorrhagic fevers $(6,24)$. There are four distinct Ebola virus species-Zaire, Sudan, Ivory Coast, and Reston $(6,24)$. Among these, the Zaire strain seems to be the most virulent, with a mortality rate for infected persons of up to $90 \%$, while the Reston strain has been less pathogenic than other species in experimentally infected nonhuman primates $(7,24)$ and has not been associated with symptomatic infection in humans. Despite extensive research, the molecular basis for the extreme virulence of the Zaire virus remains elusive.

Ebola virus is a filamentous, enveloped, negative-strand RNA virus. Its genome encodes eight proteins, with the fourth gene from the $3^{\prime}$ end of the genome encoding two glycoproteins (GPs) (5)-the envelope GP, which is responsible for receptor binding and fusion of the virus with host cell membranes $(28,32)$, and the nonstructural secretory GP, which is released from infected cells $(25,31)$. Both GPs are thought to play important but still undefined roles in Ebola virus infection (27).

Takada et al. have demonstrated previously that the infectivity of vesicular stomatitis virus (VSV) pseudotyped with the Zaire GP was enhanced by mouse anti-Zaire GP sera produced by DNA immunization, while substantially weaker enhancement was observed with anti-Reston GP sera (29). Here we present evidence indicating that antibodies able to enhance infectivity of authentic Ebola Zaire virus are produced in humans and propose a novel mechanism for this antibody-dependent enhancement (ADE) in which the complement protein C1q mediates the enhancement.

\footnotetext{
* Corresponding author. Mailing address: Division of Virology, Department of Microbiology and Immunology, Institute of Medical Science, University of Tokyo, Tokyo 108-8639, Japan. Phone: 81-3-54495504. Fax: 81-3-5449-5408. E-mail for Y. Kawaoka: kawaoka@ims .u-tokyo.ac.jp. E-mail for A. Takada: atakada@ims.u-tokyo.ac.jp.
}

\section{MATERIALS AND METHODS}

Viruses. Ebola virus (Zaire strain Mayinga) was propagated in Vero E6 cells and stored at $-80^{\circ} \mathrm{C}$ until use. All infectious materials were handled in the biosafety level 4 facility at the Canadian Science Centre for Human and Animal Health. VSV pseudotyped with Ebola GP, expressing green fluorescent protein (GFP), was generated as described previously (28). 293 and Vero E6 cells were grown in Dulbecco's minimal Eagle's medium complemented with $10 \%$ fetal bovine serum, L-glutamine, and antibiotics.

Monoclonal antibodies, human plasma, and sera. Mouse monoclonal antibodies (MAbs) were produced as described previously (29). The hybridomas producing MAbs 12/1.1 (immunoglobulin G2a [IgG2a]), 662/1.1 (IgG2a), and 746/16.2 (IgG2a), which enhance the infectivity of VSV pseudotyped with the Zaire GP, were grown in PFHM II (GIBCO BRL, Grand Island, N.Y.), and using protein A agarose columns (Bio-Rad Laboratories, Hercules, Calif.), the antibodies were purified from the supernatants. Convalescent human plasma (patients 2 to 7) and serum (patients 1 and 8) samples were obtained 51 to 135 days after onset during the 1995 outbreak in Kikwit, Democratic Republic of the Congo. In some experiments, samples of human plasma or serum were treated with $0.05 \mathrm{M}$ egtazic acid (EGTA) for $30 \mathrm{~min}$ at room temperature.

Complement and anticomplement antibody. Human complement components $\mathrm{C} 1$ and C1q (Sigma, St. Louis, Mo.) and chicken IgG purified from antiserum to human C1q (Immunsystem, Uppsala, Sweden) were used for enhancement and enhancement inhibition assays and for flow cytometric analysis.

Immunofluorescent assay (IFA). 293 cells infected with Ebola virus were fixed with $2 \%$ paraformaldehyde 1 day after infection and treated with $0.1 \%$ Triton X-100 in PBS. To detect virus-infected cells, we used rabbit antiserum to VP40 of Ebola Zaire species (12) as a primary antibody to abolish any cross-reactivity with the mouse MAb.

Virus titration. Ebola virus infectivity was quantified by counting IFA-positive cells in 5 to 10 microscopic fields. The infectivity of VSV pseudotyped with Ebola GP was determined by counting the GFP-positive cells as described previously (28). Infectivity-enhancing tests were done as described previously (29). Untreated and EGTA-treated samples of convalescent human plasma or serum (1:10 dilution) were incubated with Ebola Zaire virus for $1 \mathrm{~h}$ at room temperature and then inoculated into 293 cells. The relative percentage of infected cells was determined as the number of infected cells in the presence of normal mouse or human serum alone (approximately 20 to 50 IFA-positive cells per microscopic field) set to $100 \%$.

\section{RESULTS}

Infectivity of Ebola Zaire virus is enhanced by MAbs to GP. Takada et al. previously demonstrated that immunization of mice with the Zaire GP induces antibodies that enhance the 


\section{A}

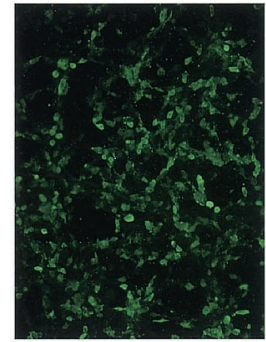

Anti-GP
antibody $+$

Normal

serum

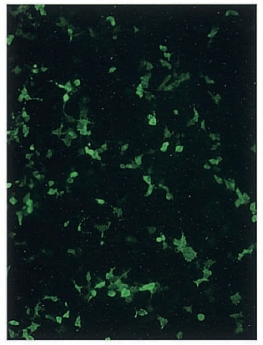

Anti-GP

antibody alone

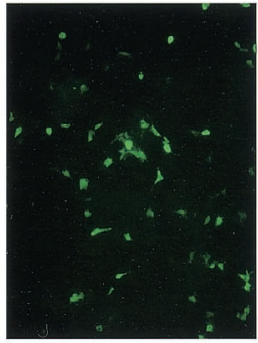

Normal serum alone

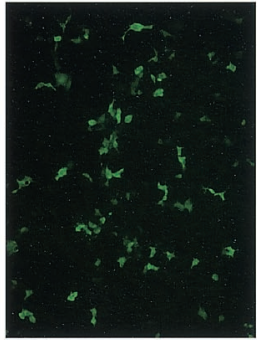

No treatment

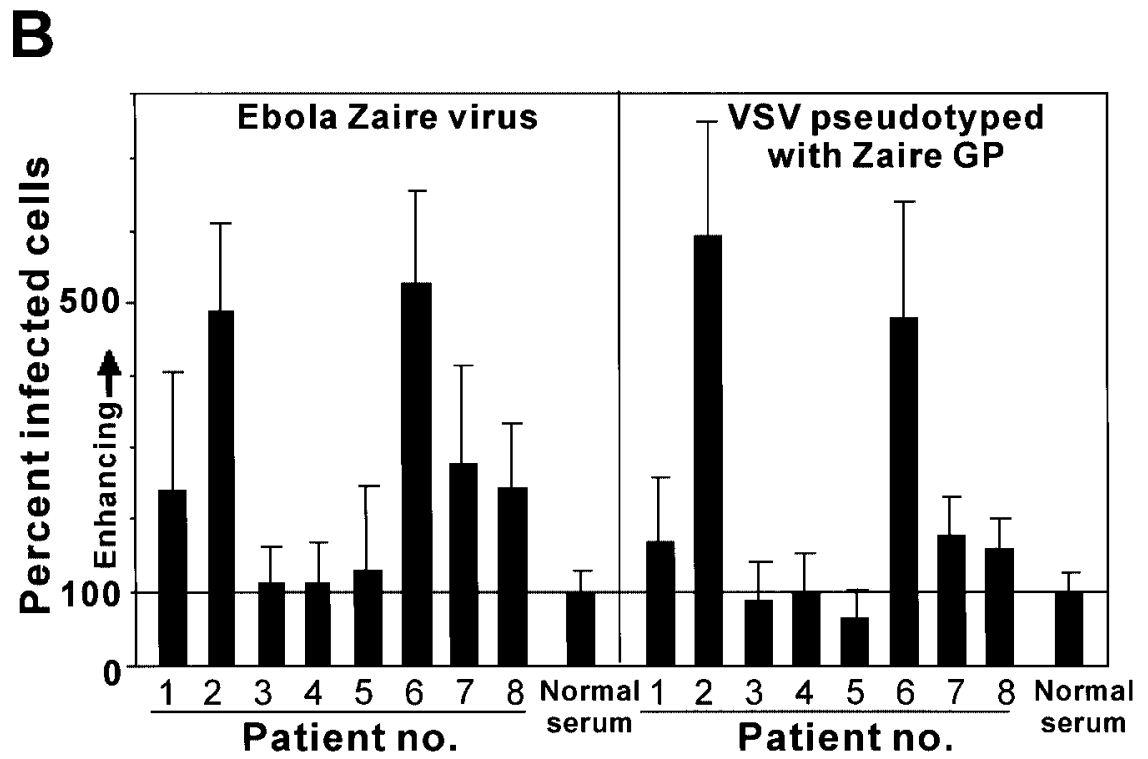

FIG. 1. ADE of Ebola virus infection. (A) 293 cells were infected with the Zaire virus in the presence or absence of purified MAb 12/1.1 (final concentration, $2 \mu \mathrm{g} / \mathrm{ml}$ ) and fresh mouse serum (final concentration, 2\%). Using rabbit anti-VP40 antiserum, infected cells were detected by IFA. (B) 293 cells were infected with the Zaire virus or VSV pseudotyped with the Zaire GP following incubation with convalescent human plasma or serum. Infected cells were detected by IFA or GFP expression. Percentages of infected cells are relative mean values ( \pm standard deviations) determined on the basis of the number of infected cells in the presence of normal human serum (100\%) for each condition.

infectivity of VSV pseudotyped with this protein and that heatlabile serum factors are required for ADE (29). To test the relevance of $\mathrm{ADE}$ for authentic Ebola virus, we infected human embryonated kidney (293) cells with the Zaire virus in the presence or absence of an anti-GP mouse MAb (MAb 12/1.1) (29). As shown in Fig. 1A, the infectivity of the virus was markedly enhanced in the presence of MAb 12/1.1 and normal mouse serum in contrast to results with a control sample lacking the antibody. Although ADE was also observed with monkey kidney cells and human umbilical vein endothelial cells, the extent of the enhancement varied with the type of cells (data not shown), suggesting that cellular molecules contribute to the enhancing effect.
Infection of humans with Ebola Zaire virus induces infectivity-enhancing antibodies. We next tested whether authentic Ebola Zaire virus infection in humans stimulates the production of antibodies capable of enhancing viral infectivity (Fig. 1B). Two of eight samples of convalescent plasma or serum (no. 2 and 6) collected from patients infected with the Ebola Zaire virus during the 1995 outbreak in Kikwit, Democratic Republic of the Congo, strikingly enhanced the infectivity of Zaire virus. This effect required prior treatment of the clinical samples with EGTA, which promotes the activity of a critical serum factor for ADE (29) (see below). Less prominent but still substantial increases in infectivity were noted for samples from three other patients (no. 1, 7, and 8). A similar pattern of 
ADE was seen in studies testing VSV pseudotyped with the Zaire GP (Fig. 1B). None of the samples showed appreciable neutralizing activity. These results indicate that human infection with authentic Ebola Zaire virus can induce antibodies that enhance viral infectivity.

Complement component 1 mediates ADE of Ebola Zaire virus infection. We have shown that ADE of infection by VSV pseudotyped with the Zaire GP requires a heat-labile serum factor that can interact with the Fc portion of the antibodies, since protein A or heat treatment reduced the infectivity-enhancing activity of antiserum to the GP (29). Although activation of the complement pathway is not involved in the ADE of Zaire virus infection (29), complement component 1 (C1), an initial component of the classical complement pathway, seemed to be a reasonable candidate for the requisite serum factor since it is heat labile, binds to antibody-antigen complexes via the Fc portion of the antibodies, and interacts with cell surface molecules $(3,16,23)$. The $\mathrm{C} 1$ complex consists of $\mathrm{C} 1 \mathrm{q}$ and two serine protease proenzymes, C1r and C1s (see Fig. 5A). Under physiologic conditions, these three molecules associate with each other in a $\mathrm{Ca}^{2+}$-dependent manner and thus can be separated by EGTA, leading to increased C1q binding to its cell surface ligands $(3,16,23)$. Separation of $\mathrm{C} 1 \mathrm{r}$ and $\mathrm{C} 1 \mathrm{~s}$ from $\mathrm{C} 1 \mathrm{q}$ is also mediated by a $\mathrm{C} 1$ inhibitor in plasma $(3,16,23)$ when $\mathrm{C} 1 \mathrm{q}$ binds to an activator $(3,16)$. Prohaszka et al. (20) suggested that C1q-mediated ADE might underlie human immunodeficiency virus (HIV) infection, but the mechanism of enhancement remains elusive, since $\mathrm{C} 1 \mathrm{q}$ directly binds to HIV gp41 $(3,15)$. Thus, we tested purified C1q for its ability to mediate ADE of Ebola Zaire virus infection.

The infectivity of the Zaire virus in cultures of 293 cells was significantly enhanced in the presence of MAb 12/1.1 and purified $\mathrm{C} 1 \mathrm{q}$ added in place of serum (Fig. 2A). This enhancement was abolished by heat treatment $\left(56^{\circ} \mathrm{C}, 60 \mathrm{~min}\right)$ of the purified protein. When treated with anti-C1q antibody, the mouse serum previously shown to be required for $\mathrm{ADE}$ of Ebola virus infection completely lost its activity (Fig. 2B), indicating that $\mathrm{C} 1 \mathrm{q}$ is in fact the serum factor required and sufficient for ADE. Addition of purified C1 (a complex of C1q, $\mathrm{C} 1 \mathrm{r}$, and $\mathrm{C} 1 \mathrm{~s}$ molecules) similarly enhanced Ebola virus infectivity, while EGTA treatment of this complex enhanced infectivity still further (data not shown). These results demonstrate that $\mathrm{ADE}$ of Ebola Zaire virus infection is mediated by the $\mathrm{C} 1 \mathrm{q}$ molecule and that dissociation of $\mathrm{C} 1 \mathrm{r}$ and $\mathrm{C} 1 \mathrm{~s}$ from $\mathrm{C} 1 \mathrm{q}$ promotes the ability of $\mathrm{C} 1 \mathrm{q}$ to mediate $\mathrm{ADE}$, resulting in increased infectivity.

GP has multiple epitopes recognized by infectivity-enhancing antibodies. In addition to MAb 12/1.1, two other MAbs to the Zaire GP (662/1.1 and 746/16.2) enhanced the infectivity of the Zaire virus but not the Reston virus (data not shown). To identify the epitopes involved, we studied VSVs pseudotyped with chimeric proteins between Zaire and Reston GPs (Fig. 3). MAbs 12/1.1, 662/1.1, and 746/16.2 recognized amino acid positions 418 to 562,1 to 232 , and 304 to 417 of the Zaire GP, respectively. We then examined the species specificity of ADE. Among three MAbs, 12/1.1 and 746/16.2 enhanced the infectivity of only VSV pseudotyped with Zaire GP, while 662/1.1 did so with VSV bearing either the Zaire or Ivory Coast GP but not the GPs of the other two strains (Fig. 4). These results

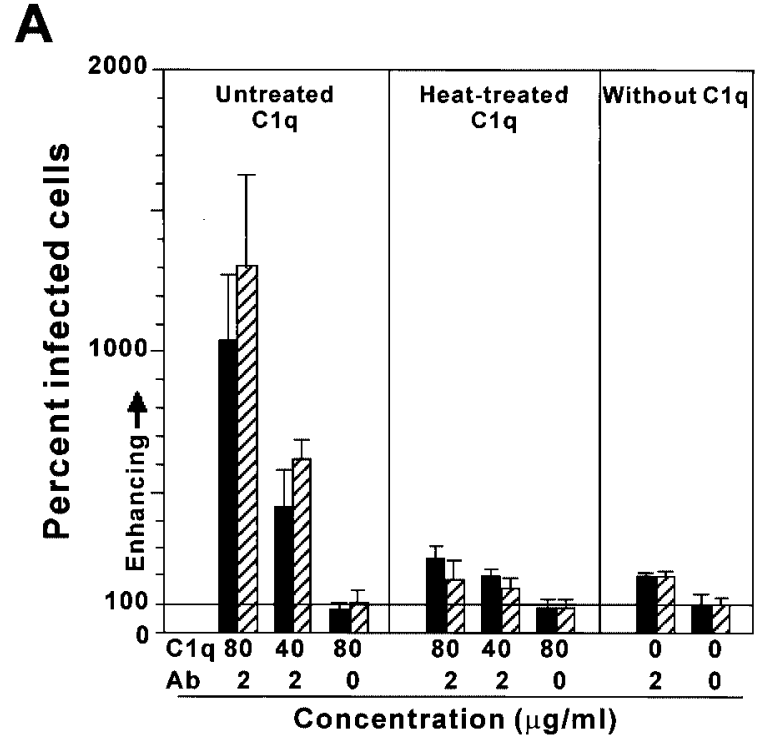

B

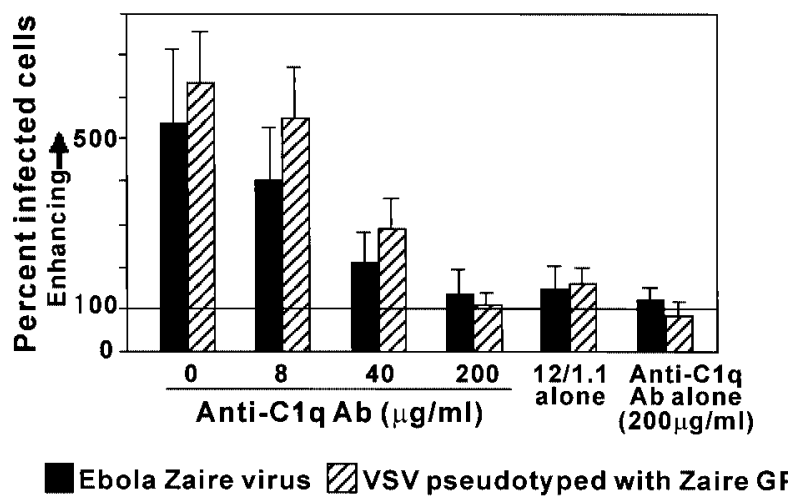

FIG. 2. C1q is required for ADE of Ebola virus infection. (A) Zaire virus or VSV pseudotyped with the Zaire GP was incubated with purified MAb 12/1.1 and untreated or heat-treated C1q. (B) Viruses were incubated with MAb 12/1.1 and 4\% mouse serum pretreated with antibodies to human C1q. Infected cells were detected by IFA. Percentages of infected cells are relative mean values $( \pm$ standard deviations) determined on the basis of the number of infected cells in the presence of normal mouse serum $(100 \%)$.

indicate the presence of multiple epitopes in the induction of ADE.

\section{DISCUSSION}

Some viruses elicit antibodies that enhance infectivity through the binding of virus-antibody complexes to cellular Fc receptors (e.g., monocytes/macrophages) via the Fc portion of the antibodies $(8,10,13,17,18,19,21,22)$. Alternatively, the complement pathway, activated by virus-antibody complexes, can facilitate virus entry, as demonstrated with the antibodydependent, complement-mediated enhancement of HIV infection (8). However, neither mechanism adequately explains the ADE of Ebola Zaire virus infection in primate kidney cells, since Fc receptors are expressed exclusively on the cells of the 


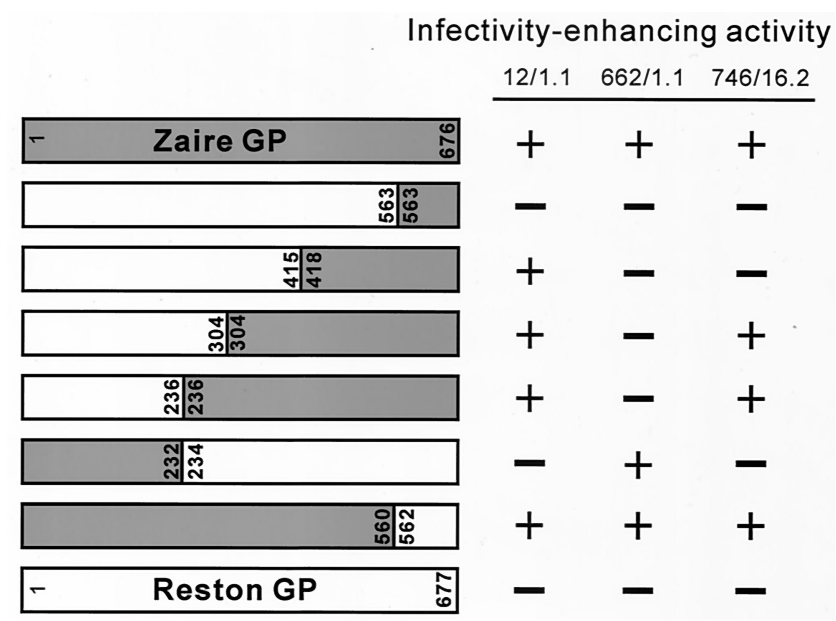

FIG. 3. Multiple epitopes on the Zaire GP are involved in ADE. VSVs pseudotyped with the chimeric GPs were incubated with MAb $12 / 1.1,662 / 1.1$, or $746 / 16.2$ in the presence of EGTA-treated mouse serum. Other experimental conditions were the same as those described in the legend for Fig. 2.

immune system, such as monocytes/macrophages, neutrophils, B cells, and granulocytes (4), and complement inhibitors did not reduce the infectivity-enhancing activity of antiserum to the Zaire GP (29).

Our findings suggest a model (Fig. 5) in which two or more molecules of monomeric IgG antibodies bind to specific GP epitopes in close proximity, allowing $\mathrm{C} 1$ to bind to the $\mathrm{Fc}$ portion of the antibodies (2). The resultant complex, consisting of the virus, antibodies, and $\mathrm{C} 1$, then binds $\mathrm{C} 1 \mathrm{q}$ ligands at the cell surface, promoting either binding of the virus to Ebola virus-specific receptors or endocytosis of the target cells by intracellular signaling via $\mathrm{C} 1 \mathrm{q}$ ligands $(3,16)$. Indeed, we confirmed by flow cytometric analysis that human C1q efficiently attaches to 293 cells (data not shown). In accord with this

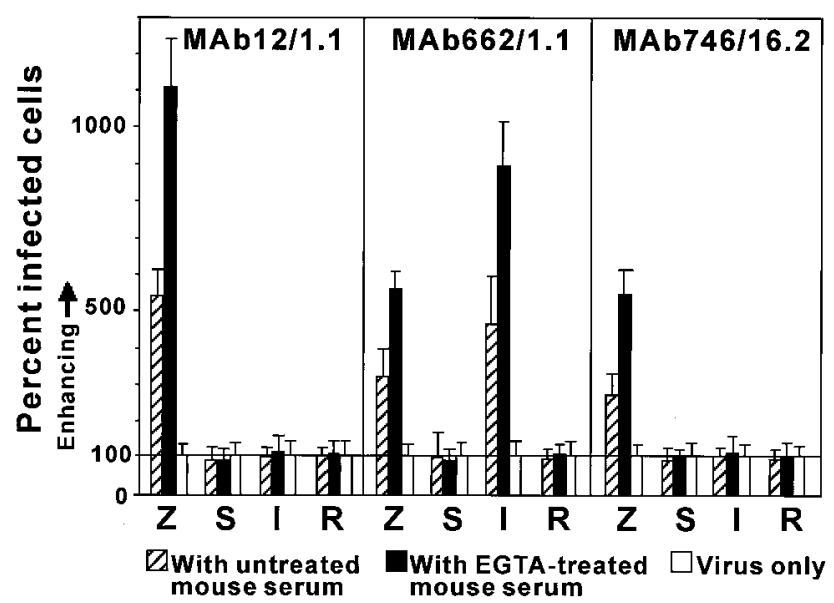

FIG. 4. Species specificity of the infectivity-enhancing MAbs. 293 cells were infected with VSV pseudotyped with Ebola Zaire (Z), Sudan (S), Ivory Coast (I), or Reston (R) GP incubated with MAb 12/1.1, $662 / 1.1$, or $746 / 16.2$ in the presence of untreated or EGTA-treated mouse serum. Other experimental conditions were the same as those described in the legend for Fig. 2.

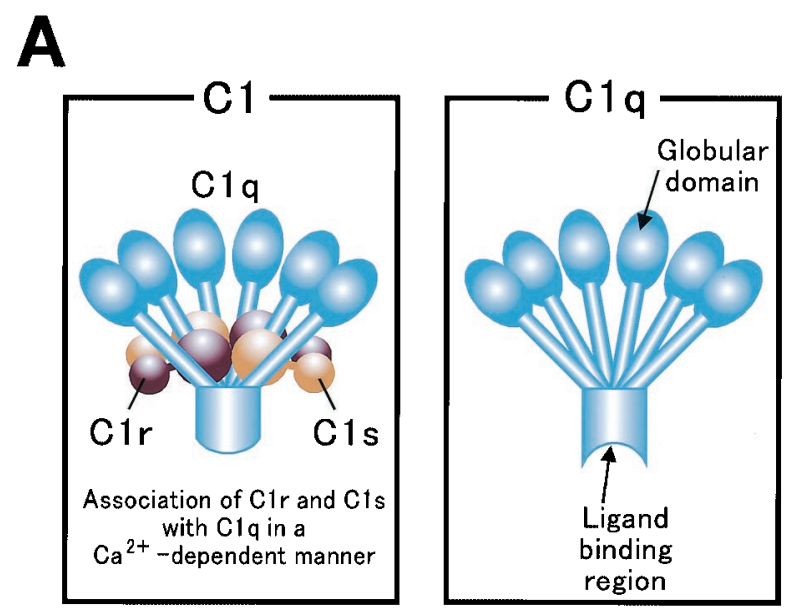

B
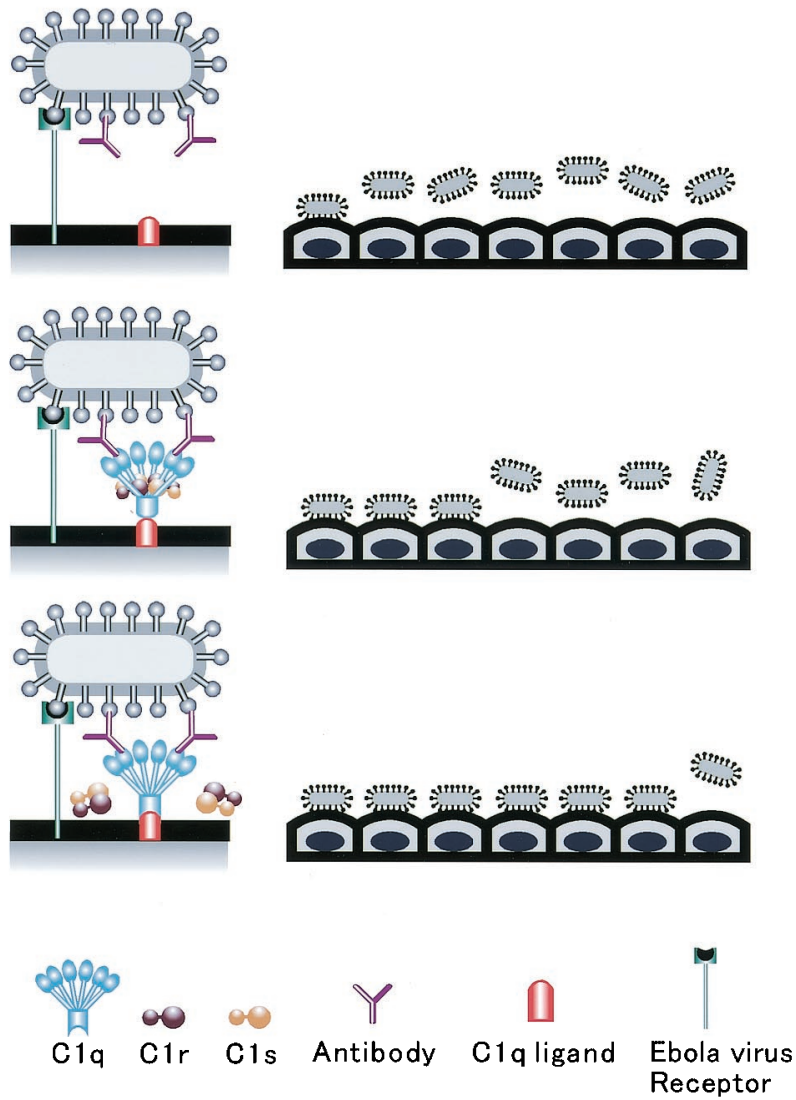

FIG. 5. C1q-mediated ADE of Ebola virus infection (model). (A) Schematic representation of complement proteins C1 and C1q. One $\mathrm{Clq}$ molecule has six globular heads that bind to the $\mathrm{Fc}$ portions of antigen-bound antibodies and one collagenous region that serves as the binding site for $\mathrm{C} 1 \mathrm{q}$ ligands present on the cell surface $(3,16,23)$. The ligand-binding affinity of $\mathrm{Clq}$ is normally reduced by its association with $\mathrm{C} 1 \mathrm{r}$ and C1s. (B) Proposed mechanism for ADE of Ebola virus infection. Ebola virus initiates infection by binding to its specific receptors (top panel). C1q enables binding between the virus-antibody complex and $\mathrm{Clq}$ ligands on the cell surface, promoting interaction between the virus and its receptor (middle panel). Binding of the virus via the $\mathrm{Clq}$ molecule increases the likelihood of viral attachment to the cell surface. Dissociation of $\mathrm{C} 1 \mathrm{r}$ and $\mathrm{C} 1 \mathrm{~s}$ from $\mathrm{Clq}$ increases binding affinity still further (bottom panel), as indicated on the right side of the model. 
model, protein A reduced the enhancing activity (29). EGTA treatment enhances ADE because the ligand-binding affinity of $\mathrm{C} 1 \mathrm{q}$ increases when $\mathrm{Ca}^{2+}$-dependent association of $\mathrm{C} 1 \mathrm{r}$ and $\mathrm{C} 1$ s with $\mathrm{C} 1 \mathrm{q}$ is disrupted $(3,16,23)$ (Fig. $5 \mathrm{~B})$. Under physiologic conditions, separation of $\mathrm{C} 1 \mathrm{r}$ and $\mathrm{C} 1 \mathrm{~s}$ from $\mathrm{C} 1 \mathrm{q}$ is mediated by a $\mathrm{C} 1$ inhibitor, normally to control harmful activation of the classical complement pathway $(3,16,23)$. The requirement for EGTA treatment in the present study was most likely due to the delayed collection of the clinical samples ( $>50$ days after disease onset) and the resultant reduction of antibody titers. C1q ligands have been identified in many cell types, including monocytes/macrophages and endothelial cells (3, $16)$, which are preferentially targeted by Ebola virus and seem to be directly involved in viral pathogenesis $(26,27)$. Thus, enhanced infection of these cells would be expected to exacerbate the hemorrhagic disease typically produced by this virus.

Both human and nonhuman primates develop virus-specific antibodies that can be detected by immunofluorescent or enzyme-linked immunosorbent assay or by Western blotting (1, 7, 11, 14). The infectivity-enhancing activity of convalescent plasma or serum in this study is likely mediated by IgG antibodies. Importantly, $\mathrm{C} 1$ binds more efficiently to polymeric $\operatorname{IgM}$ than to $\operatorname{IgG}$ antibodies (2). Since not only $\operatorname{IgG}$ but also IgM antibodies are produced in Ebola virus-infected patients, even in nonsurvivors, during the early phase of Ebola virus infection $(1,14)$, we suggest that some anti-GP IgM antibodies can contribute to the extreme virulence of Ebola virus infection. In a recent study, serum from a monkey experimentally infected with Ebola virus failed to enhance viral infectivity (9), analogous to our observation that not all samples of human convalescent plasma or serum can mediate ADE (Fig. 1B). Possibly, immune responses to the GP epitopes involved in ADE differ among infected individuals. Previous studies by Takada et al. demonstrated that mouse MAbs to the GP can be divided into three groups on the basis of their properties: neutralizing (without C1q component; unpublished data), enhancing, or nonneutralizing and nonenhancing $(29,30)$. Thus, the activities (whether enhancing, neutralizing, or neither) of the test sera can be determined by the extent of contribution from the neutralizing and enhancing antibodies and by the cell types used for the assays.

The demonstration of ADE of Ebola Zaire virus infection raises fundamental issues about the development of GP-based Ebola virus vaccines and the use of passive prophylaxis or treatment with Ebola GP antibodies. Although studies with animals indicate that GP-based Ebola virus vaccines are effective (27), the protective effect appears to depend on cytotoxic $\mathrm{T}$-cell rather than antibody responses. We suggest that such vaccines should be designed to avoid induction of known infectivity-enhancing antibodies, while passive prophylaxis with whole GP antiserum should be performed with caution.

\section{ACKNOWLEDGMENTS}

We thank Daryl Dick, Michael Garbutt, Krisna Wells, and Martha McGregor for excellent technical assistance, John Gilbert for editing the manuscript, and Yuko Kawaoka for illustrations.

This work was supported by a Grant-in-Aid for Scientific Research on Priority Areas from the Ministries of Education, Culture, Sports, Science, and Technology, Japan, to A.T., in part by the Japan Health Sciences Foundation (A.T.), by CREST (Japan Science and Technol- ogy Corporation) (A.T. and Y.K.), by National Institute of Allergy and Infectious Diseases Public Health Service research grants to Y.K., and by a research grant from the Canadian Institutes of Health Research to H.F.

\section{REFERENCES}

1. Baize, S., E. M. Leroy, M. C. Georges-Courbot, M. Capron, M. J. LansoudSoukate, P. Debre, S. P. Fisher-Hoch, J. B. McCormic, and A. J. Georges. 1999. Defective humoral responses and extensive intravascular apoptosis are associated with fatal outcome in Ebola virus-infected patients. Nat. Med. 5:423-426.

2. Borsos, T. 1992. Complement fixation test, p. 381-382. In I. M. Roitt and P. J. Delves (ed.), Encyclopedia of immunology. Academic Press, San Diego, Calif.

3. Eggleton, P., K. B. Reid, and A. J. Tenner. 1998. C1q-how many functions? How many rrs? Teceptorends Cell Biol. 8:428-431.

4. Fanger, M. W., and P. M. Guyre. 1992. Fc receptors, p. 544-549. In I. M. Roitt and P. J. Delves (ed.), Encyclopedia of immunology. Academic Press, San Diego, Calif.

5. Feldmann, H., and M. P. Kiley. 1999. Classification, structure, and replication of filoviruses. Curr. Top. Microbiol. Immunol. 235:1-22.

6. Feldmann, H., A. Sanchez, and H.-D. Klenk. 1998. Filoviruses, p. 651-664. In H. D. Collier (ed.), Topley and Wilson's microbiology and microbial infections, 9th ed. Edward Arnold, London, United Kingdom.

7. Fisher-Hoch, S. P., and J. B. McCormic. 1999. Experimental filovirus infection. Curr. Top. Microbiol. Immunol. 235:117-143.

8. Fust, G. 1997. Enhancing antibodies in HIV infection. Parasitology 115(Suppl.):S127-S140.

9. Geisbert, T. W., L. E. Hensley, J. B. Geisbert, and P. B. Jahrling. 2002. Evidence against an important role for infectivity-enhancing antibodies in Ebola virus infections. Virology 293:15-19.

10. Halstead, S. B., E. J. O'Rourke, and A. C. Allison. 1977. Dengue viruses and mononuclear phagocytes. I. Infection enhancement by non-neutralizing antibody. J. Exp. Med. 146:201-217.

11. Ignatyev, G. M. 1999. Immune response to filovirus infections. Curr. Top. Microbiol. Immunol. 235:205-217.

12. Jasenosky, L. D., G. Neumann, I. Lukashevich, and Y. Kawaoka. 2001. Ebola virus VP40-induced particle formation and association with the lipid bilayer. J. Virol. 75:5205-5214.

13. Kanno, H., J. B. Wolfinbarger, and M. E. Bloom. 1993. Aleutian mink disease parvovirus infection of mink macrophages and human macrophage cell line U937: demonstration of antibody-dependent enhancement of infection. J. Virol. 67:7017-7024.

14. Ksiazek, T. G., P. E. Rollin, A. J. Williams, D. S. Bressler, M. L. Martin, R. Swanepoel, F. J. Burt, P. A. Leman, A. S. Khan, A. K. Rowe, R. Mukunu, A. Sanchez, and C. J. Peters. 1995. Clinical virology of Ebola hemorrhagic fever (EHF): virus, virus antigen, and IgG and IgM antibody findings among EHF patients in Kikwit, Democratic Republic of the Congo, 1995. J. Infect. Dis. 179(Suppl. 1):S177-S187.

15. Marschang, P., U. Kruger, C. Ochsenbauer, L. Gurtler, A. Hittmair, V. Bosch, J. R. Patsch, and M. P. Dierich. 1997. Complement activation by HIV-1-infected cells: the role of transmembrane glycoprotein gp41. J. Acquir. Immune Defic. Syndr. Hum. Retrovirol. 14:102-109.

16. Nicholson-Weller, A., and L. B. Klickstein. 1999. C1q-binding proteins and C1q receptors. Curr. Opin. Immunol. 11:42-46.

17. Ochiai, H., M. Kurokawa, S. Matsui, T. Yamamoto, Y. Kuroki, C. Kishimoto, and K. Shiraki. 1992. Infection enhancement of influenza A NWS virus in primary murine macrophages by anti-hemagglutinin monoclonal antibody. J. Med. Virol. 36:217-221.

18. Olsen, C. W., W. V. Corapi, C. K. Ngichabe, J. D. Baines, and F. W. Scott. 1992. Monoclonal antibodies to the spike protein of feline infectious peritonitis virus mediate antibody-dependent enhancement of infection of feline macrophages. J. Virol. 66:956-965.

19. Porterfield, J. S. 1986. Antibody-dependent enhancement of viral infectivity. Adv. Virus Res. 31:335-355.

20. Prohaszka, Z., J. Nemes, T. Hidvegi, F. D. Toth, K. Kerekes, A. Erdei, J. Szabo, E. Ujhelyi, N. Thielens, M. P. Dierich, P. Spath, B. Ghebrehiwet, H. Hampl, J. Kiss, G. Arlaud, and G. Fust. 1997. Two parallel routes of the complement-mediated antibody-dependent enhancement of HIV-1 infection. AIDS 11:949-958.

21. Raabe, M. L., C. J. Issel, and R. C. Montelaro. 1999. In vitro antibodydependent enhancement assays are insensitive indicators of in vivo vaccine enhancement of equine infectious anemia virus. Virology 259:416-427.

22. Robinson, W. E., Jr., D. C. Montefiori, and W. M. Mitchell. 1988. Antibodydependent enhancement of human immunodeficiency virus type 1 infection. Lancet i:790-794.

23. Ross, G. D. 1992. Complement receptors, p. 388-391. In I. M. Roitt and P. J. Delves (ed.), Encyclopedia of immunology. Academic Press, San Diego, Calif.

24. Sanchez, A., A. S. Khan, S. R. Zaki, G. J. Nabel, T. G. Ksiazek, and C. J. Peters. 2001. Filoviridae: Marburg and Ebola viruses, p. 1279-1304. In D. M. 
Knipe and P. M. Howley (ed.), Fields virology, 4th ed. Lippincott-Williams \& Wilkins, Philadelphia, Pa.

25. Sanchez, A., S. G. Trappier, B. W. Mahy, C. J. Peters, and S. T. Nichol. 1996. The virion glycoproteins of Ebola viruses are encoded in two reading frames and are expressed through transcriptional editing. Proc. Natl. Acad. Sci. USA 93:3602-3607.

26. Schnittler, H. J., and H. Feldmann. 1999. Molecular pathogenesis of filovirus infections: role of macrophages and endothelial cells. Curr. Top. Microbiol. Immunol. 235:175-204.

27. Takada, A., and Y. Kawaoka. 2001. The pathogenesis of Ebola hemorrhagic fever. Trends Microbiol. 9:506-511.

28. Takada, A., C. Robison, H. Goto, A. Sanchez, K. G. Murti, M. A. Whitt, and Y. Kawaoka. 1997. A system for functional analysis of Ebola virus glycoprotein. Proc. Natl. Acad. Sci. USA 94:14764-14769.
29. Takada, A., S. Watanabe, K. Okazaki, H. Kida, and Y. Kawaoka. 2001. Infectivity-enhancing antibodies to Ebola virus glycoprotein. J. Virol. 75: 2324-2330.

30. Takada, A., H. Feldmann, U. Stroeher, M. Bray, S. Watanabe, H. Ito, M. McGregor, and Y. Kawaoka. 2003. Identification of protective epitopes on Ebola virus glycoprotein at the single amino acid level by using recombinant vesicular stomatitis viruses. J. Virol. 77:1069-1074.

31. Volchkov, V. E., S. Becker, V. A. Volchkova, V. A. Ternovoj, A. N. Kotov, S. V. Netesov, and H.-D. Klenk. 1995. GP mRNA of Ebola virus is edited by the Ebola virus polymerase and by T7 and vaccinia virus polymerases. Virology 214:421-430.

32. Wool-Lewis, R. J., and P. Bates. 1998. Characterization of Ebola virus entry by using pseudotyped viruses: identification of receptor-deficient cell lines. J. Virol. 72:3155-3160. 